\title{
A new approach to the synthesis of natural product Aripuanin
}

\author{
Aline Simões Lazaro ${ }^{1^{*}}(\mathrm{PG})$, Paulo Marcos Donate ${ }^{1}(\mathrm{PQ})$, Mirela Inês de Sairre ${ }^{2}(\mathrm{PQ})$. \\ ${ }^{1}$ Departamento de Química, Faculdade de Filosofia, Ciências e Letras de Ribeirão Preto, Universidade de \\ São Paulo, Avenida Bandeirantes 3900, 14040-901, Ribeirão Preto, SP, Brazil. \\ 2 Centro de Ciências Naturais e Humanas, Universidade Federal do ABC, Rua Santa Adélia 166, \\ 09210-170, Santo André, SP, Brazil.
}

*alinese@pg.ffclrp.usp.br

Keywords: Ficus, Aripuanin, Synthesis.

\section{INTRODUCTION}

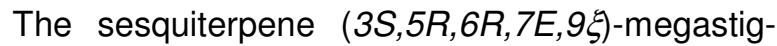
man-7-ene-3,5,6,9-tetrol, also known as Aripuanin (1), was isolated from the leaves of Ficus aripuanensis, which belongs to one of the main species of the Amazonian forest used in folk medicine for their several biological properties.

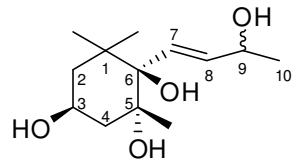

(1)

Figure 1. Structure of Aripuanin.

In this work, we describe a new synthetic route for the preparation of natural product Aripuanin (1), as outlined in Scheme 1, starting from the readily available commercial $\beta$-ionone (2).

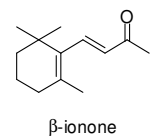

(2)

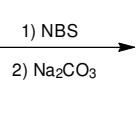

$(3)$

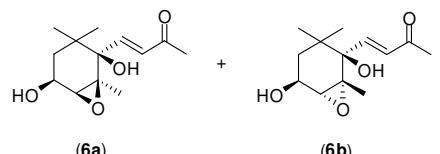

(6b)

4,5-epoxy-3,6-dihydroxy- $\alpha$-ionon
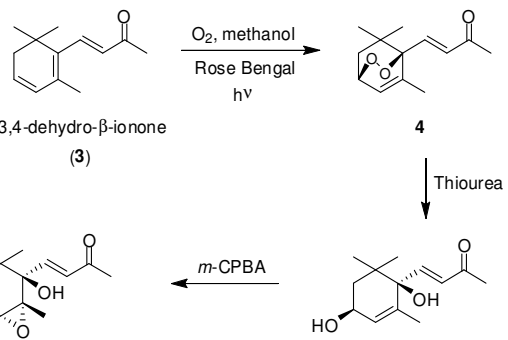

3,6-cis-dihydroxy- $\alpha$-ionone

(5)

$\mathrm{OH}$

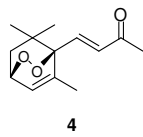

$\downarrow$ Thiourea<smiles>CC(O)/C=C/[C@]1(O)C(C)(C)C[C@H](O)C[C@@]1(C)O</smiles>

6a $1 a^{\prime}$

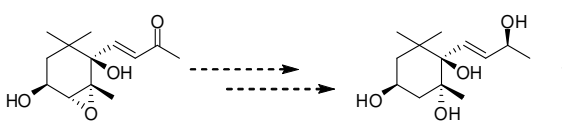

$6 b$

\section{CONCLUSION}

The results obtained so far demonstrate the feasibility of this new synthetic route and indicate that the desired natural product 1 can be prepared successfully. Moreover, our goal is also to correctly assign the stereochemistry of the several stereogenic centers present in the natural product.

\section{ACKNOWLEDGEMENTS}

FAPESP, CAPES, CNPq.

\section{REFERENCES}

${ }^{1}$ M. Nascimento et al.; Fitoterapia 1999, 70, 628.

${ }^{2}$ S. Serra et al.; Tetrahedron Asymm. 2007, 18, 2573.

Scheme 1. Preparation of the Aripuanin (1). 